\title{
Comparing Genetic Value of Bulls from Different Breeds: Across Breed EPDs 1
}

Gary R. Hansen ${ }^{2}$

\section{Introduction}

Using expected progeny differences (EPDs) has revolutionized beef cattle breeding. EPDs estimate the differences expected in performance of future progeny of two or more sires of the same breed within the same analysis. Many cattle producers routinely use EPDs to select sires to meet their production goals. However, cattlemen that use cross breeding systems are using sires from several breeds. This makes selection decisions more difficult as EPDs from different breed associations are not comparable. Each breed association publishes EPDs either annually or semi-annually for birth weight, weaning weight, yearling weight, milking ability and maternal weaning weight (total maternal). These EPDs are specific to the breed for which they were generated and cannot be compared to other breeds because the base point or base year is different in each breed. Researchers at the U. S. Meat Animal Research Center (MARC) in Clay Center, Nebraska have developed tables that present adjustment factors to account for differences between different breeds. Only breeds with sires included and evaluated in the MARC Germplasm Evaluation Program have across-breed adjustment factors estimated. These adjustment factors allow for the calculation of across-breed expected progeny differences

(AB-EPDs).

\section{Using AB-EPDs}

The table of adjustment factors can be used to estimate AB-EPDs for sixteen beef cattle breeds. AB-EPDs adjustment factors are updated each year using the most recent national cattle evaluations conducted by each breed association. The adjustment factors reflect not only current breed differences but also differences in base point for which average EPDs equals zero for each breed. Thus, the adjustment factors alone are not estimates of average breed differences. The adjustment factors are based on "head to head" comparison of progeny as well as sire EPDs at MARC. Through the use of these adjustment factors, AB-EPDs are calculated that will allow for EPD comparison across breeds.

Adjustment factors for 2005 are listed in Table 1.

Across-breed EPDs are most useful to commercial producers that are purchasing several different sire breeds to use in systematic crossbreeding programs. One of the major problems

1. This document is AN162, one of a series of the Animal Science Department, Florida Cooperative Extension Service, Institute of Food and Agricultural Sciences, University of Florida. Original publication date March 27, 2006. Visit the EDIS Web Site at http://edis.ifas.ufl.edu.

2. Hansen, G.R., Assistant Professor of Animal Science, University of Florida, North Florida Research and Education Center, Marianna, Florida, Cooperative Extension Service, Institute of Food and Agricultural Sciences, University of Florida, Gainesville, 32611.

The Institute of Food and Agricultural Sciences (IFAS) is an Equal Opportunity Institution authorized to provide research, educational information and other services only to individuals and institutions that function with non-discrimination with respect to race, creed, color, religion, age, disability, sex, sexual orientation, marital status, national origin, political opinions or affiliations. U.S. Department of Agriculture, Cooperative Extension Service, University of Florida, IFAS, Florida A. \& M. University Cooperative Extension Program, and Boards of County Commissioners Cooperating. Larry Arrington, Dean 
in using crossbreeding systems is the lack of uniformity that results when dissimilar sires from different breeds are utilized. Through the use of AB-EPDs, producers can come closer to identifying sires that are similar in terms of their genetic potential for the desired traits they want to incorporate in their breeding program. For example, producers using a rotational cross breeding system would use AB-EPDs to select for birth weight to help alleviate calving problems as well as keep cow size and milk production to manageable levels while still having acceptable growth in their calves. Producers using a terminal cross breeding systems could use AB-EPDs to manage growth traits by selecting bulls (from different breeds) that are similar for growth traits. Heifers would benefit from sires that have low birth weight $A B-E P D s$ which would minimize excessive birth weights while still utilizing heterosis in their offspring.

\section{Calculating AB-EPDs}

To estimate AB-EPDs, current EPDs from the respective breed associations along with the current across-breed adjustment factors are needed. For example, assume that the current weaning weight EPD for a Simmental bull is $+39 \mathrm{lb}$ (2005 average breed $\mathrm{EPD}=+34 \mathrm{lb}$ ) and for a Charolais bull is +25 $\mathrm{lb}(2005$ average breed EPD $+21.1 \mathrm{lb})$. The AB-EPD adjustment factors (see table 1) are 22.8 for Simmental bulls and 38.8 for Charolais bulls. The calculated AB-EPDs for the Simmental bull is 61.8 $(39+22.8=61.8)$ and for the Charolais bull is 63.8 $(25+33.8=63.8)$. The expected weaning weight difference when both bulls are mated to cows of a different breed would be two pounds $(63.8-61.8=$ 2.0).

Notice that the adjustment factors for Angus cattle are zero for all of the traits. The Angus breed is used as the base breed from which the factors are estimated. The Angus breed was chosen as the base breed because they are the largest breed in North America and they have a fixed base year. The AB-EPDs for an Angus sire would be his actual EPDs computed by the American Angus Association as the adjustment factor is zero.
Use of AB-EPDs when selecting bulls to use in a crossbreeding program from several breeds is illustrated in Table 2. If a producer has the goal of producing cattle that excel in growth traits (terminal cross program) and has a different breed than Charolais or Simmental, then these two bulls could be used on a comparable basis in his herd. If a producer is interested in producing maternal breeds, then some of the other breeds listed would work in his program. Cattle that are produced in the subtropics/tropics would benefit from the Bos indicus influenced genetics especially when considering breeds to use as female replacements.

\section{Summary}

When selecting breeds and animals within breeds, consideration needs to be given to where animals will be raised and marketed. Market participation is becoming as much a part of the equation in today's beef industry as the environment. Knowing how to optimize resources for your particular herd with regards to environmental constraints, while targeting animals that will be able to compete in the marketplace will be crucial to surviving in the beef cattle industry. Target your market and then work backwards to identify the right animals. To summarize how to utilize AB-EPDs in your breeding program, consider the following points:

1) Know where your cow herd is in relation to your targets, while understanding that your cow herd still has to produce in your environment.

2). Know where in the production chain the offspring will be marketed. Will you sell them as calves or retain ownership through slaughter? Where do they fit on a value-based grid? Are they best marketed as stockers, yearlings, or replacement females?

3). Identify the breeds and animals within those breeds (primarily bulls) that will move the cow herd in the right direction to optimize production within the environment while hitting market endpoints. Producers must be realistic and practical to insure selection of the correct type of animals. 
One note of caution in using AB-EPDs: there are

no accuracy values estimated when these types of EPDs are calculated, so risk is hard to assess. Also adjustment factors were generated in a temperate environment and research has shown that Bos-indicus-influenced cattle will have higher production levels when performance is measured in subtropical/tropical environments. However, with this said, AB-EPDs are still the best methodology available for producers to assess genetic potential across different breeds. 
Table 1. Adjustment Factors to Add to EPDs of Sixteen Different Breeds to Estimate Across-Breed EPDs for 2005.

\begin{tabular}{|c|c|c|c|c|}
\hline Breed & Birth Weight & Weaning Weight & Yearling Wt & Milk \\
\hline Angus & 0.0 & 0.0 & 0.0 & 0.0 \\
\hline Brahman & 12.5 & 35.6 & -4.9 & 24.9 \\
\hline Brangus & 5.1 & 19.6 & 19.9 & -3.6 \\
\hline Braunvieh & 6.0 & 30.2 & 12.8 & 22.4 \\
\hline Beefmaster & 9.2 & 39.5 & 37.5 & -4.6 \\
\hline Charolais & 10.0 & 38.8 & 53.2 & 1.8 \\
\hline Gelbvieh & 4.7 & 6.3 & -22.3 & 2.4 \\
\hline Hereford & 2.9 & -1.8 & -14.2 & -18.8 \\
\hline Limousin & 4.0 & 1.8 & -20.8 & -16.2 \\
\hline $\begin{array}{l}\text { Maine- } \\
\text { Anjou }\end{array}$ & 6.3 & -5.3 & -41.7 & -9.4 \\
\hline Red Angus & 3.1 & -1.0 & 0.7 & -6.8 \\
\hline Salers & 4.2 & 29.0 & 42.3 & 9.9 \\
\hline Shorthorn & 7.3 & 32.0 & 44.7 & 12.9 \\
\hline Simmental & 5.9 & 22.8 & 21.8 & 10.1 \\
\hline $\begin{array}{l}\text { South } \\
\text { Devon }\end{array}$ & 6.2 & 21.9 & 41.0 & 4.5 \\
\hline Tarentaise & 3.1 & 30.6 & 13.1 & 18.3 \\
\hline
\end{tabular}

Table 2. Using AB-EPDs to compare bulls of various breeds (2005).

\begin{tabular}{||l|l|c|c|c|c||}
\hline \hline Breed/Bull Name & \multicolumn{1}{|c|}{ Factor/EPD } & BW & WW & YRLWT & Milk \\
\hline Angus & EPD & 1.5 & 43 & 84 & 33 \\
\hline New Design 878 & Adjustment Factor & 0.0 & 0.0 & 0.0 & 0.0 \\
\hline & AB-EPD & $\mathbf{1 . 5}$ & $\mathbf{4 3}$ & $\mathbf{8 4}$ & $\mathbf{3 3}$ \\
\hline & & & & & \\
\hline Simmental & EPD & 1.0 & 45.6 & 94.8 & -1.9 \\
\hline Lucky Dice & Adjustment Factor & 5.9 & 22.8 & 21.8 & 10.1 \\
\hline & AB-EPD & $\mathbf{6 . 9}$ & $\mathbf{6 8 . 4}$ & $\mathbf{1 1 6 . 6}$ & $\mathbf{8 . 2}$ \\
\hline & & & & & \\
\hline Charolais & EPD & 0.4 & 33 & 61 & 7 \\
\hline \hline
\end{tabular}


Table 2. Using AB-EPDs to compare bulls of various breeds (2005).

\begin{tabular}{|c|c|c|c|c|c|}
\hline Grid Marker & Adjustment Factor & 10.0 & 38.8 & 53.2 & 1.8 \\
\hline & AB-EPD & 10.4 & 71.8 & 114.2 & 8.8 \\
\hline Branqus & EPD & 0.6 & 37.9 & 64.8 & 18.1 \\
\hline Brinks Cadence & Adjustment Factor & 5.1 & 19.6 & 19.9 & -3.6 \\
\hline $13 F$ & AB-EPD & 5.7 & 57.5 & 84.7 & 14.5 \\
\hline Beefmaster & EPD & -2.3 & 18 & 36 & 7 \\
\hline \multirow[t]{2}{*}{ Cloud Dancing } & Adjustment Factor & 9.2 & 39.5 & 37.5 & -4.6 \\
\hline & AB-EPD & 6.9 & 57.5 & 73.5 & 2.4 \\
\hline Hereford & EPD & 3.5 & 38 & 72 & 25 \\
\hline \multirow[t]{2}{*}{ HR Robin Hood } & Adjustment Factor & 2.9 & -1.8 & -14.2 & -18.8 \\
\hline & AB-EPD & 6.4 & 36.2 & 57.8 & 6.2 \\
\hline Red Angus & EPD & 0.3 & 40 & 85 & 25 \\
\hline \multirow[t]{2}{*}{ Cheyenne } & Adjustment Factor & 3.1 & -1.0 & 0.7 & -6.8 \\
\hline & AB-EPD & 4.1 & 39.0 & 84.3 & 18.2 \\
\hline
\end{tabular}

